NBER WORKING PAPER SERIES

ASSESSING DYNAMIC EFFICIENCY: THEORY AND EVIDENCE

Andrew B. Abe 1

N. Gregory Mankiw

Lawrence $H$. Summers

Richard J. Zeckhauser

Working Paper No. 2097

\author{
NATIONAL BUREAU OF ECONOMIC RESEARCH \\ 1050 Massachusetts Avenue \\ Cambridge, MA 02138 \\ December 1986
}

\begin{abstract}
We are grateful to David Bradford, Stanley Fischer, and Philippe Weil for comments, and to the National Science Foundation, the Amoco Foundation, and the Sloan Foundation for financial support. The research reported here is part of the NBER's research programs in Economic Fluctuations and Productivity. Any opinions expressed are those of the authors and not those of the National Bureau of Economic Research.
\end{abstract}


NBER Working Paper \#2097

December 1986

\section{Assessing Dynamic Efficiency: Theory and Evidence}

\section{ABSTRACT}

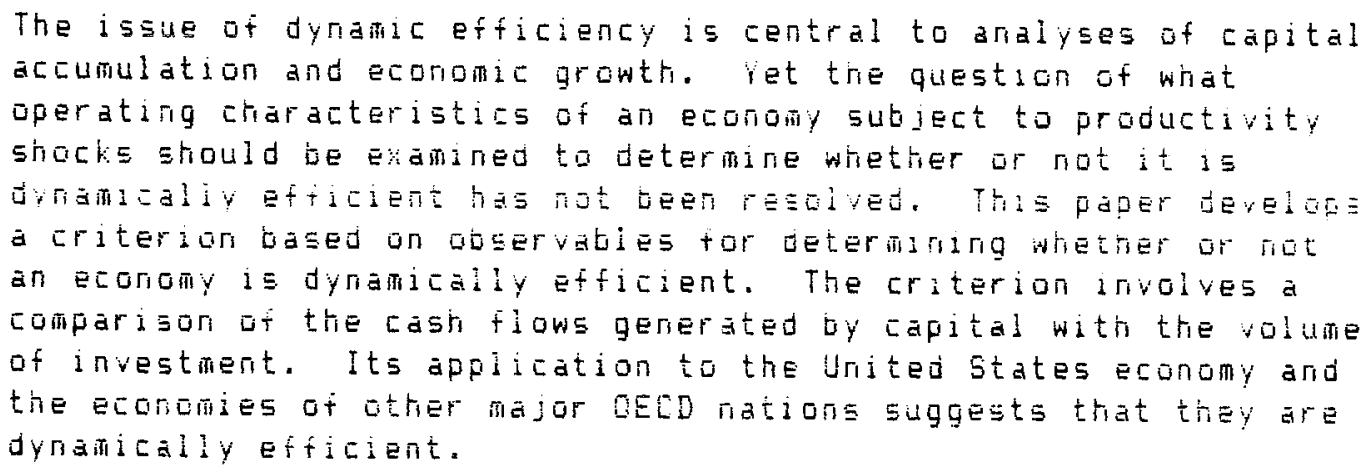

Andrew B. Abel

Department of Finance

The Wharton School

Steinberg Ha11, Room 2319

University of Pennsylvania

Philadelphia, PA 19104

Lawrence $H$. Summers

Department of Economics

Littauer Center

Harvard University

Cambridge, MA 02138
N. Gregory Mankiw Department of Economics Littauer Center Harvard University Cambridge, MA 02138

Richard J. Zeckhauser Kennedy School of Government Harvard University 79 John F. Kennedy Street Cambridge, MA 02138 
Dynamic efficiency is a central issue in analyses of economic growth, the effects of fiscal policies, and the pricing of capital assets. In a celebrated article, Peter Diamond (1965) shows that a competitive economy can reach a steady state in which there is unambiguously too much capital. In situations where the population growth rate exceeds the steady state marginal product of capital, or equivalently the economy is consistently investing more than it is earning in profit, the economy is said to be dynamically inefficient. In the terminology of Phelps (1961), the capital stock exceeds its Golden Rule level. A Pareto improvement can be achieved in a dynamically inefficient economy by allowing the current generation to devour a portion of the capital stock and then holding constant the consumption of all future generations.

Recent work suggests that dynamic efficiency is crucial for issues of positive as well as normative economic analysis. Weil (1986) argues that dynamic efficiency is a necessary condition for an altruistic bequest motive to be operative and thus for the Ricardian equivalence theorem of Barro (1974) to hold. Tirole (1985) shows that speculative bubbles can arise as rational expectations equilibria of dynamically inefficient economies, but are ruled out if dynamic efficiency prevails.

Whether actual economies operate above or below the Golden Rule level of capital intensity is a question of substantial importance. Many authors take the position that the United States economy is dynamically efficient. Such a presumption must underlie optimal growth arguments for increased national savings, such as those presented by Tobin (1965), Solow (1970), and Feldstein (1977). These authors base their judgment that the economy is dynamically 
efficient on estimates of the marginal productivity of capital derived from observed accounting profit rates. Such calculations (e.g., Feldstein and Summers (1977)) suggest that the marginal productivity of capital is about 10 percent, far above the economy's growth rate, and thus indicate the economy is dynamically efficient.

Yet there is an alternative, and on its face equally plausible, procedure for judging whether an economy is dynamically efficient - looking at the safe real interest rate, such as the return on Treasury bills. Unlike the accounting profit rate, the short-term real interest rate can be measured with 'little ambiguity, and contains at most a negligible risk premium. Feldstein (1976), in arguing against the Ricardian equivalence proposition, explicitly compares the economy's growth rate and real interest rate. Numerous other authors in a variety of contexts also note that real interest rates on safe assets are typically less than economic growth rates. Ibbotson (1984) reports that the mean real return on Treasury bills over the 1926-1983 period was roughily zero percent, well under the economy's average growth rate. Data on other nations, such as those presented by Mishkin (1984), suggest that interest rates are less than growth rates in other countries as well. This comparison of real interest rates and growth rates seems to suggest that mature capitalist economies have overaccumulated capital.

In abstract growth models like Diamond's, there is no difference between the marginal product of capital, which might be inferred from data on profits and the capital stock, and the real interest rate on safe government securities. Nor are there fluctuations in the economy's growth rate or in the relative value of capital goods. Such models therefore give little guidance 
as to which features of actual economies should be examined in assessing dynamic efficiency. To address this issue, it is necessary to examine models in which profitability, the value of capital, and the growth rate are uncertain, so that the distinction between the marginal productivity of capital and the interest rate on safe government securities is a meaningful one. This paper examines the conditions for dynamic efficiency in such models. Our goal is to ascertain what observable features of actual economies can be used to make inferences about dynamic efficiency and then to assess whether the United States economy is dynamically efficient.

We begin by generalizing the original Golden Rule result of Phelps (1961) and others: an economy is dynamically efficient if it invests less than the return to capital and is inefficient if it invests more than the return to capital. This result applies to a stochastic setting with a very general production technology. In a competitive economy, therefore, the issue of dynamic efficiency can be resolved by comparing the level of investment with the cash flows generated by production after the payment of wages. More metaphorically, the key question is whether the capital sector is on net a spout or a sink. This criterion has the substantial virtue of not requiring any information on capital gains and losses, and not requiring the use of accounting conventions in the measurement of profit. Its application to the United States economy suggests very clearly that it is dynamically efficient. The economy has always (since 1929 at least) consumed a substantial portion of the return to capital. Similar results obtain for other developed capitalist economies as well.

While we argue that the net cash flow criterion is the most natural and 
general way to think about the issue of dynamic efficiency, much of the discussion of the issue centers on comparisons of rates of return and growth rates. We therefore present results characterizing the circumstances under which a comparison of growth rates and rates of return can determine whether an economy is dynamically efficient. Our conclusion is that the appropriate criterion involves evaluations of whether asset returns dominate the growth in wealth valued in terms of consumption goods. That is, dynamic efficiency cannot be assessed by comparing the safe rate of interest and the average growth rate of the capital stock, output, or any other accounting aggregate. Rather, the safe rate must be compared with the rate of growth of the market value of the capital stock. In actual economies, where the market value of existing capital goods fluctuates widely and declines frequently, this comparison is unlikely to render any verdict about dynamic efficiency. While these results suggest we are safe in concluding that economies like that of the United States are dynamically efficient, some troubling questions remain. Why, if physical assets that always yield a positive return are available, is the safe rate of interest so low? If the safe rate of interest is zero or negative, why don't infinitely-lived productive assets have an infinite value? If the safe rate of interest is below the economy's growth rate, can't a pay-as-you-go social security system be Pareto-improving? To address these questions, we present a simple example highlighting the potential importance of capital price risk in determining asset values. We show that in a dynamically efficient economy where output evolves as a geometric random walk with positive drift, the safe rate of interest over all horizons may at all times be negative. This example makes clear that 
comparisons of the safe rate of interest and average growth rates are misleading for the purpose of assessing dynamic efficiency.

The paper is organized as follows. Section I develops our cash flow criterion for assessing the dynamic efficiency of an economy and applies it to United States data. Section II considers rate of return criteria for dynamic efficiency. Section III highlights the role of capital price risk in accounting for the low observed level of safe interest rates. Section IV concludes the paper by calling attention to a number of issues requiring further research.

\section{A General Criterion for Dynamic Efficiency}

Here we examine a generalization of the economy studied by Diamond (1965). There are two crucial differences between Diamond's overlapping generations model and ours. First, we allow both the rate of population growth and the production technology to be stochastic. Second, our production technology is very general; it allows, as special cases, for costs of adjustment, time-to-build, vintage capital, and embodied and disembodied technological progress. Unlike the technology typically assumed in one-sector growth models, our general production technology allows for fluctuations in the relative price of claims on existing capital goods and consumption. This feature of the model is important, because much of the risk associated with holding capital in actual economies involves uncertainty about capital gains and losses arising from changes in the relative price of capital. 


\section{A. The Economy}

Each individual lives for two periods and maximizes a von Neumann-Morgenstern utility function that, for simplicity, is additively separable over consumption in the two periods. Thus, individuals maximize

$$
u\left(c_{t}^{y}\right)+E_{t} v\left(c_{t+1}^{0}\right)
$$

where $c_{t}^{y}$ is the consumption of a young person in period $t, c_{t+1}^{0}$ is the consumption of an old person in period $t+1$, and $E_{t}$ is the expectation conditional on information available at time $t$.

There are $\mathrm{N}_{t}$ individuals in the cohort born at time $t$. The young supply their labor inelastically, and the old do not work, so $N_{t}$ is also the labor supply in period t. Each young person consumes some of the return to his labor and invests the rest by buying shares in the new and existing firms that compose the market portfolio. In old age, he receives dividends from his shares, sells them ex dividend to the young cohort, and consumes the total proceeds.

An individual therefore faces the following budget constraint:

$$
c_{t}^{y}=w_{t}-v_{t} s_{t}
$$

$$
c_{t+1}^{0}=\left(D_{t+1}+v_{t+1}\right) s_{t}
$$

where $w_{t}$ is the wage, $s_{t}$ is his share of the market portfolio, $v_{t}$ is the total value of the market portfolio ex dividend, and $D_{t}$ is the total dividend. Letting $R_{t+1}$ denote the return on any asset between period $t$ and period $t+1$, then the standard first-order condition for capital asset pricing is 
(1.4) $\quad E_{t}\left[\frac{v^{\prime}\left(c_{t+1}^{0}\right) R_{t+1}}{u^{\prime}\left(c_{t}^{y}\right)}\right]=1$.

Equation (1.4) of course holds also for the return on the market portfolio, for which $R_{t+1}=R_{t+1}^{M} \equiv\left(v_{t+1}+D_{t+1}\right) / v_{t}$.

A few identities are instructive. Aggregate consumption $c_{t}$ is

$$
c_{t} \equiv N_{t} c_{t}^{y}+N_{t-1} c_{t}^{0}
$$

and the aggregate share is $\mathrm{N}_{t} \mathrm{~s}_{t}=1$. Equations (1.2) and (1.3) therefore imply that consumption is labor income plus the dividend:

$$
C_{t} \equiv w_{t} N_{t}+D_{t}
$$

Let $Y_{t}$ be gross output, $\pi_{t} \equiv Y_{t}-W_{t} N_{t}$ be profit, and $I_{t} \equiv Y_{t}-C_{t}$ be investment. Equation (1.6) implies

$$
D_{t} \equiv \pi_{t}-I_{t}
$$

The dividend as we define it equals profit less investment. (Equivalently, the dividend equals consumption less labor income.) Note that a repurchase of shares by firms is represented here as a dividend payment. Similarly, a new equity issue is a negative dividend. The dividend thus represents the net flow of goods from firms to households (except of course for labor income), and there is no presumption regarding its sign.1

Firms produce output from capital and labor. We assume that the production technology is:

$$
Y_{t}=F\left(I_{t-1}, I_{t-2}, \cdots I_{t-n} ; N_{t}, \theta_{t}\right)
$$


where $I_{t}$ is the gross investment in period $t$, and $\theta_{t}$ is the state of nature in period $t$. Note that the technology expressed in equation (1.8) is very general. Under the common assumption that capital fully depreciates each period, each period's investment equals next period's capital stock, so $Y_{t}=F\left(I_{t-1} ; N_{t}, \theta_{t}\right)$. A dependence of output on past investment, however, arises if there are costs of adjustment of capital. It also arises if, as is plausible, capital does not fully depreciate each period and the type of capital built each period varies because of changes in the available technology.

We assume that the technology has constant returns to scale. That is, $F($.$) is homogeneous of degree one in past investment and current labor supply.$ The competitive wage is therefore

$$
w_{t}=\partial F\left(I_{t-1}, I_{t-2}, \cdots I_{t-n} ; N_{t}, \theta_{t}\right) / \partial N_{t} \text {. }
$$

The total return to capital is

$$
\text { (1.10) } \pi_{t}=\sum_{i=1}^{\alpha_{1}} F_{t}^{i} I_{t-i}
$$

where $F_{t}^{i}$ indicates the partial derivative of $F($.$) with respect to vintage t-i$ investment. We assume that $F_{t}^{i} \geqslant 0$. The specification in (1.8) implies that $F_{t}^{i} \equiv 0$ for $i>n$. Equation (1.10) says that profits are composed of return to capital of all vintages.

An equilibrium of this economy is a set of state-contingent allocations and market prices that satisfies all the individual and economywide constraints and that also satisfies the first-order condition (1.4). We are interested in characterizing the conditions under which such an equilibrium is dynamically efficient or inefficient. 
B. Dynamic Efficiency

Let $\Omega\left(\theta_{t}\right)$ be the ex ante utility of generation $t$ given that this generation is born in state of nature $\theta_{t}$. That is,

$$
\Omega\left(\theta_{t}\right)=u\left(c_{t}^{y}\left(\theta_{t}\right)\right)+E\left(v\left(c_{t+1}^{o}\left(\theta_{t+1}\right)\right) \mid \theta_{t}\right) .
$$

We call an initial equilibrium dynamically inefficient if it is possible to increase $\Omega\left(\theta_{s}\right)$ for some $\theta_{s}$ without decreasing $\Omega\left(\theta_{t}\right)$ for any other $\theta_{t}$; if such

a Pareto improvement is impossible, an equilibrium is dynamically efficient.

Consider a social welfare function

$$
w=v\left(c_{0}^{0}\right)+\sum_{t=0}^{\alpha} \sum_{\theta_{t}} \mu\left(\theta_{t}\right) \Omega\left(\theta_{t}\right)
$$

where $\mu\left(\theta_{t}\right)$ is the weight the social planner gives to $\Omega\left(\theta_{t}\right)$.

An equilibrium is dynamically efficient if it maximizes social welfare $W$ for some set of positive weights $\mu\left(\theta_{t}\right)$. It is important to stress the nature of the social welfare function in equation (1.12). In the unfettered equilibrium, there are no private markets in which individuals can insure against the state of nature in which they are born. Since our concern in this paper is the issue of overaccumulation, and not intergenerational risk-sharing, we do not call an equilibrium inefficient if the absence of these insurance markets is the only market failure. Formally, we allow the social planner to apply separate social planning weights to the same individual born in different states of nature.

We now turn to the principal result of this paper: 
Proposition 1: If $D_{t} / V_{t} \geqslant \epsilon>0$ in all periods and all states of nature, then the equilibrium is dynamically efficient. If $D_{t} / V_{t} \leqslant-\epsilon<0$ in all periods and all states of nature, then the equilibrium is dynamically inefficient.

This proposition states that if goods are on net always flowing out of firms to investors, then the equilibrium is efficient. Conversely, if goods are on net always flowing into firms from investors, then the equilibrium is inefficient. Our proposition is a generalization of the Golden Rule result of Phelps (1961): an economy that invests more than its total profit in steady state is dynamically inefficient.

The familiar condition from the Diamond model for dynamic efficiency is that the marginal product of capital ( $r$ ) exceeds the growth rate of population (n). Note that the growth rate of population equals the growth rate of the capital stock in Diamond's steady state. Therefore, since rk is the total return on the aggregate capital stock $K$ and $n K$ is new investment, the net flow out of firms (the dividend) is $r k$ - nK. Hence, while Proposition 1 is much more general, it is consistent with the traditional criterion in the steady state of Diamond model.

The proof of efficiency is in the Appendix. The proof of inefficiency follows.

C. Proof of Inefficiency

Following Cass (1972), we provide a constructive proof of the inefficiency condition by illustrating a Pareto-improving intervention that is feasible if the inefficiency condition is satisfied. Suppose that in period 1 the consumption of each old consumer is increased by $\delta$ and the consumption of 
the current young consumers and the consumptions of all future generations are left unchanged. Clearly, such a change would be Pareto-improving. If such a change is feasible, then the initial equilibrium was inefficient.

Since aggregate consumption in period 1 is increased by $\delta N_{0}$, the change in aggregate investment, $d_{1} I_{1}$, is equal to $-\delta N_{0}$. This reduction in $I_{1}$ implies that output will be reduced by $F_{2}^{1} d_{1}$ in period 2 . Since consumption in period 2 is to remain unchanged, investment must fall by the same amount as output (1.13) $\quad \mathrm{dI}_{2}=\mathrm{F}_{2}^{1} \mathrm{dI}_{1}$.

In each subsequent period the reduction in output must be matched by a fall in investment of the same magnitude, so that, differentiating the production function, we obtain

$$
d I_{t}=\sum_{i=1}^{n} F_{t}^{i} d I_{t-i}
$$

Now define $\Delta_{t} \equiv d I_{t} / I_{t}$ to be the proportional change in period $t$ investment. Using this definition and dividing both sides of (1.14) by $I_{t}$ yields a homogeneous linear difference equation in $\Delta_{t}$,

$$
\Delta_{t}=\sum_{i=1}^{n}\left(F_{t}^{i} I_{t-i} / I_{t}\right) \Delta_{t-i}
$$

If the proportional change in investment $\Delta_{t}$ is always finite and approaches zero as $t$ goes to infinity, then, for an appropriately small $\delta$, the intervention is feasible. Therefore, if the coefficients $F_{t}^{i} I_{t-i} / I_{t}, i=1$, $\ldots, n$, in the difference equation (1.15) are always positive and sum to less than one, then the intervention is feasible.

It remains to show that the condition $D_{t} / V_{t} \leqslant-\epsilon<0$ implies that 
$\sum_{i=1}^{n}\left(F_{t}^{i} I_{t-i} / I_{t}\right)<1$. We suppose that $D_{t} / V_{t} \leqslant-\epsilon<0$ and use $(1.7)$ and $(1.10)$ to obtain

$$
\left[\left(\sum_{i=1}^{n} F_{t}^{i} I_{t-i}\right)-I_{t}\right] / V_{t} \leqslant-\epsilon<0
$$

Observing that $0 \leqslant I_{t} / V_{t} \leqslant 1$, equation (1.16) implies

$$
\left[\left(\sum_{i=1}^{n} F_{t}^{i} I_{t-i}\right)-I_{t}\right] / v_{t} \leqslant-\epsilon I_{t} / V_{t}<0
$$

Equation (1.17) implies directly that

$$
\sum_{i=1}^{n} F_{t}^{i} I_{t-i} / V_{t} \leqslant(I-\epsilon) I_{t} / V_{t}
$$

Dividing both sides of $(1.18)$ by $I_{t} / V_{t}$ yields

$$
\sum_{i=1}^{n} F_{t}^{i} I_{t-i} / I_{t} \leqslant 1-\epsilon<1
$$

which is the condition that coefficients in the linear difference equation (1.15) sum to less than one. Therefore, if $D_{t} / V_{t} \leqslant-\epsilon<0$, then the proposed Pareto-improving intervention is feasible.

Q.E.D.

\section{Applying the Cash Flow Criterion}

The criterion derived above for determining whether an economy is dynamically efficient can be applied relatively easily to actual economies. Unlike the criteria applied in many previous applications of optimal growth 
models (e.g., Solow (1970)), our criterion does not depend critically on accounting judgments about depreciation or the measurement of profits in an inflationary environment. It requires only the comparison of the cash flows going into and coming out of an economy's production sector. 2 As the preceding discussion makes clear, the applicability of our criterion depends on the assumption that capital receives its marginal product, an assumption that excludes the possibility that capital income includes substantial monopoly profit.

We apply our criterion to the United States economy and to the economies of several other major countries. While the theory developed above is most directly applicable to the economy as a whole, we examine the U.S. nonfinancial corporate sector as well, for two reasons. First, many popular discussions of the desirability of increased capital formation refer to corporate investment rather than investment in housing. Second, in measuring the rental income generated by owner-occupied housing, one must use estimates of imputed rents, rather than direct measurements of market transactions. Fortunately, the calculations for the economy as a whole and the calculations for the corporate sector yield very similar results. Both suggest that our criterion for dynamic efficiency has been satisfied by a wide margin in all years.

Table 1 presents information on gross capital income, gross investment, and their difference, all expressed as fractions of gross national product (GNP) for the 1929-1985 period. Gross capital income is measured as national income less employee compensation and an estimate of the labor income of proprietors plus capital consumption allowances. Alternatively, it can be 
thought of as the sum of profit, rental, and interest income. ${ }^{3}$ Gross investment includes investment in both residential and nonresidential capital along with increases in inventories. Their difference corresponds to the "dividend," D, paid by firms. For the period 1952-1985, for which an estimate of the market value of the economy's tangible assets is available, the table also presents the ratio $D / V$, which plays a key role in the preceding analysis. The data indicate very clearly that capital has consistently generated more income than has been reinvested. Indeed, the difference between capital income and investment has exceeded 15 percent of GNP in every year - since 1929. Put differently, the economy has never invested much more than half of its gross capital income. The final column of the table indicates that the divideno generated by capital has consistently exceeded 4 percent of total wealth. Given the downward trend in the ratio of the dividend to GNF and the upward trend in the ratio of total wealth to GNP, it is fairly certain that the dividend generated by capital exceeded 4 percent during the entire 1929-1985 period.

Table 2 presents calculations paralleling those in Table 1 for the nonfinancial corporate sector. Outflow from the nonfinancial corporate sector (D) is defined as the sum of dividends, interest payments, and corporate tax payments, less net financial investments. Except for a statistical discrepancy, this outflow in turn equals the difference between gross pretax operating profits and gross capital investment. (Again, investment is measured as including both purchases of plant and equipment and increases in inventories.) In all calculations, the denominator is the market value of the corporate sector measured as the sum of the market value of outstanding 
equity, and net financial liabilities as reported in the National Balance Sheets. The results establish that for the 1952-1985 period gross capita? income far exceeded gross investment. Indeed, in most years, the disparity is somewhat greater for the corporate sector than it is for the aggregate economy. This finding is not surprising given the heavier tax burdens placed on corporate capital. It appears clear from these calculations that the corporate sector is on net productive, in the sense that net outflows of cash from the corporate sector are positive.

Table 3 presents values of D/GNP for England, France, Germany, Italy, Canada and Japan for the 1960-1984 period. Examining the dynamic efficiency of economies other than the U.S. economy is of interest because the American savings rate has traditionally been much lower than that of other countries. Japan in particular, with its high rate of accumulation and tradition of low real interest rates, seems a plausible candidate for inefficiency. Yet the data reveal that our criterion for dynamic efficiency is comfortably satisfied for all countries in all years. Countries like Japan with higher investment rates also have higher rates of profit. In 1984, for example, the U.S. invested 16 percent of GNP and had gross capital cash flow of 28 percent of GNP. For Japan, the corresponding figures were 28 percent and 38 percent. The calculations in Tables 1-3 show that our criterion for dynamic efficiency has been very decisively satisfied for the world's major capitalist economies. Yet as Phelps emphasized in his initial development of the Golden Rule, a path cannot be judged as dynamically efficient or dynamically inefficient prior to eternity. That is, dynamic efficiency cannot in principle be judged by observing only a particular segment of time. These 
calculations do allow us to conclude, however, that if the economy behaves in the future as it has in the past, it will be realizing a dynamically efficient equilibrium.

\section{Using Rates of Return to Diagnose Overaccumulation}

In Section I we presented sufficient conditions for dynamic efficiency and dynamic inefficiency expressed in terms of investment and profit. Much of the literature on dynamic efficiency expresses the relevant conditions in terms of rates of return and growth rates. In this section we examine how one can compare rates of return and growth rates to assess dynamic efficiency.

Recall that the rate of return on the market portfolio, $R_{t+1}^{M}$, is equal to $\left(V_{t+1}+D_{t+1}\right) / V_{t}$. Defining $G_{t+1} \equiv v_{t+1} / V_{t}$ as the growth rate of the value of the market portfolio we obtain

$$
R_{t+1}^{M} / G_{t+1} \equiv 1+D_{t+1} / V_{t+1}
$$

Equation (2.1) immediately implies the following corollary to Proposition 1.

Corollary 1: If $R_{t}^{M} / G_{t} \geqslant 1+\epsilon>1$ in all periods and all states of nature, then the equilibrium is dynamically efficient. If $R_{t}^{M} / G_{t} \leqslant 1-\epsilon<1$ in all periods and all states of nature, then the equilibrium is dynamically inefficient.

Corollary 1 states that the rate of return on capital can be used in assessing whether the economy is dynamically efficient. The condition for efficiency in Corollary 1 will be satisfied if the dividend is always greater 
than zero.

A more general result is also available for assessing dynamic efficiency. The competitive rate of return on any other asset can also be potentially useful in determining whether the economy is dynamically efficient or inefficient. Let $R_{t+1}$ be the competitive rate of return between period $t$ and period $t+1$ on an arbitrary asset. In the Appendix we present an extension of the proof of Proposition 1 that proves the following Proposition:

Proposition 2: If there is some asset with rate of return $R_{t}$ such that $R_{t} / G_{t} \geqslant 1+\epsilon>1$ in all periods and all states of nature, then the equilibrium is dynamically efficient. If there is some asset with rate of return $R_{t}$ such that $R_{t} / G_{t} \leqslant 1-\epsilon<1$ in all periods and all states of nature, then the equilibrium is dynamically inefficient.

This result can be applied in the special case of the safe interest rate. It says that if an economy's safe interest rate is always greater than the growth rate of the market value of the capital stock, the economy is dynamically efficient. If the safe rate is always less than the growth rate of the value of the capital stock, the economy is dynamically inefficient. Neither proposition is very helpful in judging the dynamic efficiency of actual economies, where capital gains and losses cause the growth of the market value of the capital stock sometimes to exceed and other times to fall short of the safe interest rate. The result here is illuminating primarily in suggesting that comparisons of safe interest rate with the average growth rate are in general not sufficient to resolve the issue of dynamic efficiency. 


\section{Capital Price Risk and the Low Level of Safe Interest Rates}

The previous section suggests that a safe interest rate below an economy's average growth rate is not sufficient to establish dynamic inefficiency. This conclusion may at first seem surprising. If all the investments an economy is making are productive, how can the safe interest rate be so low? More generally, how can the measured rate of profit suggest that the marginal product of capital is so high at the same time that the real interest rate is so low? These questions differ from the puzzle regarding the equity risk premium raised by Mehra and Prescott (1985). Mehra and Prescott ask why, given the wide spread between mean equity and debt returns and given the limited variability of consumption, consumers do not try to borrow to buy equity, thereby reducing the mean equity premium. Here the question is why low interest rates can persist given the consistently high level of the average product of capital. To pose the question starkly, can physical assets that always yield a positive dividend have a finite value when real interest rates are zero or negative?

A basic answer to these questions lies in the notion of capital price risk. The principal risks associated with the ownership of capital do not involve the rents it will generate in the succeeding period, but rather involve the possibility of changes in its market value. Individuals considering the ownership of capital take account of these risks. Even if an asset will always be productive, individuals are exposed to the $r$ isk that its price will decline if anticipated future profits fall off, or if the demand for wealth declines. Such risks explain how a low safe rate can coincide 
permanently with a high rate of profit in a dynamically efficient economy. We illustrate this point with a simple example based on Lucas's (1978) analysis of asset pricing. In contrast to the preceding sections, we assume here that there is a single representative infinitely lived consumer. Since the competitive outcome in this case replicates the solution to the social planning problem of maximizing the utility of the representative consumer, we know it is dynamically efficient. (As we shall see, application of our criterion from Section I leads to the same conclusion.) An infinite horizon example is used to highlight the fact that the importance of capital risk in no way depends on the finiteness of individual lifetimes.

Consumers are assumed to maximize the infinite horizon utility function:

$$
E_{t} \sum_{i=0}^{\alpha} \beta^{i} U\left(C_{t+i}\right)
$$

The economy's only productive asset is a "fruit tree" whose output evolves as a geometric random walk with positive drift. It is not possible to produce or cut down the fruit tree. The output of the fruit tree, all of which is consumed in each period, thus evolves as:

$$
D_{t}=D_{t-1}\left(1+g+v_{t}\right)
$$

where $g>0$ and $\nu_{t}$ is i.i.d. with zero mean, and $\nu_{t}>-(1+g)$. Note that in this example capital income, $D_{t}$, is always positive and thus always exceeds the economy's zero level of investment, so our criterion for dynamic efficiency is satisfied.

Assets in this economy are easily priced by making use of the consumer's first-order condition: 


$$
E_{t}\left\{R_{t+1} \beta U^{\prime}\left(C_{t+1}\right) / U^{\prime}\left(C_{t}\right)\right\}=1
$$

where $R_{t}$ is the gross return on any asset.

Now suppose the utility function is logarithmic, $U(C)=\ln (C)$, and recall that $C_{t} \equiv D_{t}$, so that $(3.3)$ can be written as

$$
E_{t}\left\{R_{t+1} \beta /\left(1+g+\nu{ }_{t+1}\right)\right\}=1 \text {. }
$$

Equation (3.4) can be used to price any asset. In particular, the gross rate of return on a riskless asset, $R_{t+1}^{F}$, is constant and given by

$$
R_{t+1}^{F}=\frac{1}{E_{t}\left[\frac{\beta}{1+g+\nu_{t+1}}\right]} .
$$

If the variance of $\nu$ is sufficiently large, it is clear $R_{t+1}^{F}$ can be less than one, so that the net interest rate can be negative despite the upward drift in output. 4 since the safe short-term rate is constant, safe interest rates over any horizon are also negative as long as output is sufficiently volatile.

Equation (3.4) can also be used to determine $v_{t}$, the value of the stock of fruit trees. Since the rate of return on a fruit tree is $\left(V_{t+1}+D_{t+1}\right) / V_{t}$, equation (3.4) verifies

$$
\text { (3.6) } \quad v_{t}=\left(\frac{\beta}{1-\beta}\right) D_{t}
$$

Despite the uncertainty in this model economy, the dividend-price ratio is constant. It is straightforward to show that the mean return on the fruit tree is $(1+g) / \beta$, regardless of the amount of uncertainty. Hence, increases in 
uncertainty raise the risk premium solely by lowering the risk-free rate. This example makes clear that because of asset-price risk, permanently productive assets can exist in equilibrium with a negative real rate of interest, and that such a situation can easily be efficient. A low safe interest rate, even a negative rate in perpetuity, need not imply that the economy is overcapitalized.

The example suggests the limited validity of arguments based on comparisons of the safe rate of return and the average growth rate of output. For simplicity, suppose the safe rate is negative and the mean growth rate is positive. It has been argued that a pay-as-you-go social security scheme that transferred one dollar from young to old in each period would be Pareto improving, and so it would. But as long as output can conceivably fall in each period, the feasibility of such a scheme is not guaranteed. The fact that output has an arbitrarily high probability of rising as the horizon is lengthened is not sufficient to assure feasibility. Internally, the argument here parallels the well-known fallacy regarding the appropriateness of investing only in high-yielding assets over long horizons, discussed monosyllabically by Samuelson (1979). In both cases, "almost surely" is not certain enough.

Our "fruit tree" example shows that a low safe rate of interest need not imply dynamic inefficiency. Yet the results of Mehra and Prescott (1985) suggest that additional considerations, such as market imperfections, may be necessary to explain the observed low safe rate. The interaction between these imperfections and dynamic efficiency may be important. For example, some individuals may be liquidity constrained, so that the relevant interest 
rate for evaluating a hypothetical Social Security scheme exceeds the safe rate of interest. Considering dynamic efficiency in "distorted" economies is a worthwhile subject for future research.

\section{Conclusion}

In the literature on optimal accumulation and dynamic efficiency, substantial intellectual capital has been put into place since the early 1960s. Yet despite this investment and the growing policy concern over capital formation, no clear answer has emerged as to whether actual economies are dynamically efficient. To address the issue of dynamic efficiency in practice, it is imperative to recognize the impact of uncertainty on production, investment, and growth. The goal of this paper has therefore been to extend dynamic efficiency results to an uncertain world.

Our central finding is simply expressed. If the capital sector is regularly contributing to the level of consumption, then the economy is dynamically efficient. If it is a continual drain, then the economy is inefficient. In the United States, profit has exceeded investment in every year since 1929. This finding leads us to conclude that the United States economy is dynamically efficient.

Established tradition suggests that dynamic efficiency is to be evaluated by comparing growth rates and rates of return on assets. In an uncertain world, there is no obvious metric for economic growth; nor is there a single rate of return. The appropriate indicator of dynamic efficiency is the rate of growth of the value of the capital stock, as measured in consumption goods. 
If the rate of return on any asset dominates this rate, the economy is dynamically efficient. If the return on any asset is dominated by this rate, the economy is dynamically inefficient. While this rate-of-return criterion is theoretically valid, we believe it is less useful in practice than the cash flow criterion for assessing dynamic efficiency.

We started this analysis with the troubling observation that real interest rates are startlingly low. We reassured ourselves by demonstrating that low, or even negative, safe rates, even in perpetuity, need not indicate dynamic inefficiency. Our fruit-tree example suggests that asset price risk could in principle explain the low safe rate, but we have made no attempt to measure this risk. 5

Our conclusion that the United States economy is dynamically efficient has several important corollaries. First, Tirole (1985) shows that rational speculative bubbles are ruled out in dynamically efficient economies. 6 We suspect, but have not proven, that Tirole's result generalizes to economies with uncertainty. Our results thus call into doubt the existence of rational bubbles of the sort Tirole examines. 7

Second, Weil (1986) shows that an interior bequest motive, of the sort on which Barro (1974) relies, can be ruled out in dynamically inefficient economies. Again, we suspect that this result generalizes to uncertain settings. Our finding of dynamic efficiency, however, suggests that such a bequest motive cannot be ruled out. In contrast to the conclusion of Feldstein (1976), the low safe rate of interest may not preclude Ricardian equivalence.

While it is comforting that our cash flow criterion leads unambiguousiy 
to the conclusion that our economy is dynamically efficient, several questions remain open for future research. The most important direction for future research is the evaluation of alternative dynamic paths using stronger criteria than the dynamic efficiency criterion. Our criterion is the dynamic analogue of the standard pareto criterion. The dynamic efficiency test is therefore relatively weak -- passing it does not imply that a path is desirable for any very attractive social welfare function. Results characterizing the social welfare functions necessary to justify particular paths would aid in evaluating and ranking them.

The importance of going beyond the Pareto criterion is greater in the context of dynamic efficiency than in the normal static context. As we have already noted, a path cannot be judged as dynamically inefficient prior to eternity, because there is always the possibility that "excess" capital will be consumed later. Using social welfare functions would permit, at least sometimes, judgments that regardless of what happened in the indefinite future, certain policies maintained over finite intervals would be undesirable. Putting the point differently, the use of social welfare functions would make possible the evaluation of alternative social decision rules for determining the level of investment.

Risk-sharing considerations, which we have systematically excluded from our analysis, provide yet another reason for introducing a social welfare function. Programs such as social security have the ability to spread risks across generations. We dodged the possibility of ex ante risk-spreading bargains by treating individuals born at the same time under different realizations of the world as being on different, separately evaluated paths. 
But given that social security or tax and expenditure policy can promote ex ante risk spreading, such risk spreading could be considered in studies that follow. 


\section{Appendix}

Proof of Proposition 1 (Efficiency):

The social planner maximizes social welfare (1.12) subject to the set of constraints

$$
N_{t} c_{t}^{Y}+N_{t-1} c_{t}^{0}+I_{t}=F\left(I_{t-1} \cdot I_{t-2}, \cdots I_{t-n} ; N_{t}, \theta\right)
$$

for all $\theta_{t}$. The Lagrangian for the social planner is

$$
\begin{aligned}
L & \left.=v\left(c_{0}^{0}\right)+\sum_{t=0}^{\alpha} \sum_{\theta_{t}} \mu\left(\theta_{t}\right)\left\{u\left(c_{t}^{y}\left(\theta_{t}\right)\right)+\sum_{\theta_{t+1}} p\left(\theta_{t+1}\right] \theta_{t}\right) v\left[c_{t+1}^{0}\left(\theta_{t+1}\right)\right]\right\} \\
& -\sum_{t=0}^{\alpha} \sum_{\theta} \lambda\left(\theta_{t}\right)\left(N_{t}\left(\theta_{t}\right) c_{t}^{y}\left(\theta_{t}\right)+N_{t-1}\left(\theta_{t-1}\right) c_{t}^{o}\left(\theta_{t}\right)\right. \\
& \left.+I_{t}\left(\theta_{t}\right)-F\left(I_{t-1}, I_{t-2} \cdots I_{t-n} ; N_{t}, \theta_{t}\right)\right\}
\end{aligned}
$$

where $p\left(\theta_{t+1} \mid \theta_{t}\right)$ denotes the probability of $\theta_{t+1}$ given that $\theta_{t}$ occurs. The variable $\theta_{t}$ is a vector indexing the state of nature in $t+1$ including history up to $t+1$.

The first-order conditions are

$(A .3)$

$$
v^{\prime}\left(c_{0}^{O}\right)=\lambda_{0} N_{-1}^{\prime}
$$

(A.4) $\quad \mu\left(\theta_{t}\right) u^{\prime}\left[c_{t}^{y}\left(\theta_{t}\right)\right]=\lambda\left(\theta_{t}\right) N_{t}\left(\theta_{t}\right)$,

$$
\mu\left(\theta_{t-1}\right) p\left(\theta_{t} \mid \theta_{t-1}\right) v^{\prime}\left[c_{t}^{O}\left(\theta_{t}\right)\right]=\lambda\left(\theta_{t}\right) N_{t-1}\left(\theta_{t-1}\right) \text {, for } \theta_{t} \mid \theta_{t-1} \text {, }
$$

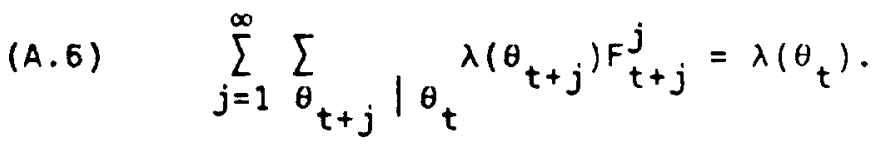


The expression $\theta_{t+j} \mid \theta_{t}$ denotes those states of nature in $t+j$ that can follow from $\theta_{t}$. The transversality condition requires

(A.7) $\quad \lim _{t \rightarrow \infty} \sum_{\theta_{t}} \lambda\left(\theta_{t}\right) V\left(\theta_{t}\right)=0$

where

$$
\sum_{\theta_{t}} \lambda\left(\theta_{t}\right) V\left(\theta_{t}\right)=\sum_{j=0}^{\infty} \sum_{i=1}^{\infty} \sum_{\theta_{t+j+1}} \lambda\left(\theta_{t+j+1}\right) F_{t+j+1}^{j+i}\left(\theta_{t+j+1}\right) I_{t+1-i}\left(\theta_{t+1-i}\right) .
$$

If the initial equilibrium satisfies these conditions for some set of positive weights $\mu\left(\theta_{t}\right)$ and multipliers $\lambda\left(\theta_{t}\right)$, the equilibrium is efficient.

Equation (A.3) defines the initial Lagrangian multiplier $\lambda_{0}$. Equations (A.4) and (A.5) then uniquely define all multipliers $\lambda\left(\theta_{t}\right)$ and social planning weights $\mu\left(\theta_{t}\right)$, given the initial equilibrium. Thus, to show that the equilibrium solves a planning problem, we need only show that (A.6) and (A.7) are satisfied.

The first-order condition (A.6) follows from the capital market equilibrium condition (1.4). To see this, let $q_{t+j}^{j}$ be the price (relative to consumption) at the end of period $t+j$ of a unit of investment installed in period $t$. Observe $q_{t}^{0}=1$ and $q_{t}^{n}=0$. Let $R_{t+j+1}^{j+1}$ be the rate of return between period $t+j$ and period $t+j+1$ on a unit of capital installed in period $t$. Therefore,

$$
\text { (A.9) } R_{t+j+1}^{j+1}\left(\theta_{t+j+1}\right)=\left[F_{t+j+1}^{j+1}\left(\theta_{t+j+1}\right)+q_{t+j+1}^{j+1}\left(\theta_{t+j+1}\right)\right] / q_{t+j}^{j}\left(\theta_{t+j}\right) \text {. }
$$

Using (A.9), the capital market equilibrium condition (1.4) implies 
(A.10)

$$
\begin{aligned}
q_{t+j}^{j}\left(\theta_{t+j}\right)= & \sum_{\theta_{t+j+1}}\left[F_{t+j+1}^{j+1}\left(\theta_{t+j+1}\right)+q_{t+j+1}^{j+1}\left(\theta_{t+j+1}\right)\right] x \\
& P\left(\theta_{t+j+1} l \theta_{t+j}\right) v^{\prime}\left[c_{t+j+1}^{0}\left(\theta_{t+j+1}\right)\right] / u^{\prime}\left[c_{t}^{y}\left(\theta_{t+j}\right)\right] .
\end{aligned}
$$

Now observe from $(A .4)$ and (A.5) that

$$
p\left(\theta_{t+j+1} \mid \theta_{t+j}\right) v^{\prime}\left[c_{t+j+1}^{0}\left(\theta_{t+j+1}\right)\right] / u^{\prime}\left[c_{t+j}^{y}\left(\theta_{t+j}\right)\right]=\lambda\left(\theta_{t+j+1}\right) / \lambda\left(\theta_{t+j}\right),
$$

for $\theta_{t+j+1} \mid \theta_{t+j}$. Substituting (A.11) into (A.10) yields

(A.12) $q_{t+j}^{j}\left(\theta_{t+j}\right)=\sum_{t+j+1} \mid \theta_{t+j}\left[F_{t+j+1}^{j+1}\left(\theta_{t+j+1}\right)+q_{t+j+1}^{j+1}\left(\theta_{t+j+1}\right)\right] \lambda\left(\theta_{t+j+1}\right) / \lambda\left(\theta_{t+j}\right)$.

Now recall that $q_{t}^{0}=1$ and solve (A.12) recursively forward to obtain

$$
\lambda\left(\theta_{t}\right)=\sum_{j=0}^{\infty} \sum_{t+j+1} \theta_{t} F_{t+j+1}^{j+1}\left(\theta_{t+j+1}\right) \lambda\left(\theta_{t+j+1}\right),
$$

which is equivalent to $(A .6)$.

To establish efficiency, we still need to show that the transversality condition (A.7) is satisfied. From equation (A.8), we know that

(A.14) $\sum_{\theta_{t}} \lambda\left(\theta_{t}\right) V\left(\theta_{t}\right)=\sum_{\theta_{t+1}} \sum_{i=1}^{\alpha} \lambda\left(\theta_{t+1}\right) F_{t+1}^{i} I_{t+1-i}+\sum_{j=1}^{\infty} \sum_{i=1}^{\infty} \sum_{\theta_{t+j+1}} \lambda\left(\theta_{t+j+1}\right) F_{t+j+1}^{j+i} I_{t+1-i}$.

(Some arguments specifying the state of nature are omitted where there is no ambiguity.) The first term on the right-hand side of this inequality equals $\sum_{\theta_{t+1}} \lambda\left(\theta_{t+1}\right) \pi_{t+1}$. The second term can be rewritten with $j$ running from zero and $i$ running from two:

(A.15) $\sum_{\theta_{t}} \lambda\left(\theta_{t}\right) V\left(\theta_{t}\right)=\sum_{\theta_{t+1}} \lambda\left(\theta_{t+1}\right) \pi_{t+1}+\sum_{j=0}^{\infty} \sum_{i=2}^{\infty} \sum_{\theta_{t+j+2}} \lambda\left(\theta_{t+j+2}\right) F_{t+j+2}^{j+i} I_{t+2-i}$. 
$-29-$

The second term can now be written using (A.8) as the sum of $\lambda\left(\theta_{t+1}\right) V\left(\theta_{t+1}\right)$ and a remainder, producing

(A.16)

$$
\begin{aligned}
\sum_{\theta_{t}} \lambda\left(\theta_{t}\right) V\left(\theta_{t}\right) & =\sum_{\theta_{t+1}} \lambda\left(\theta_{t+1}\right) \pi_{t+1}+\sum_{\theta_{t+1}} \lambda\left(\theta_{t+1}\right) V\left(\theta_{t+1}\right) \\
& -\sum_{j=0}^{\infty} \sum_{t+j+2} \lambda\left(\theta_{t+j+2}\right) F_{t+j+2}^{j+1} I_{t+1} .
\end{aligned}
$$

The third term of $(A .16)$ can be rewritten as

(A.17) $\quad \sum_{j=0}^{\alpha} \sum_{\theta_{t+j+2}}^{\alpha} \lambda\left(\theta_{t+j+2}\right) F_{t+j+2}^{j+1} I_{t+1}=\sum_{j=1}^{\alpha} \sum_{\theta_{t+j+1}}^{\alpha\left(\theta_{t+j+1}\right) F_{t+j+1}^{j} I_{t+1}}$

by beginning the index at $j$ at one rather than zero. This expression is now identically

(A.18) $\quad \sum_{j=0}^{\alpha} \sum_{\theta_{t+j+2}} \lambda\left(\theta_{t+j+2}\right) F_{t+j+2}^{j+1} I_{t+1}=\sum_{j=1}^{\alpha} \sum_{\theta_{t+1}} \sum_{t+j+1} \mid \theta_{t+1} \lambda\left(\theta_{t+j+1}\right) F_{t+j+1}^{j} I_{t+1}$.

Equation (A.6) now implies

(A.19) $\quad \sum_{j=0}^{\infty} \sum_{\theta_{t+j+2}} \lambda\left(\theta_{t+j+2}\right) F_{t+j+2}^{j+1} I_{t+1}=\sum_{\theta_{t+1}} \lambda\left(\theta_{t+1}\right) I_{t+1}$.

Therefore, returning to (A.16),

$(A .20)$

$$
\sum_{\theta_{t}} \lambda\left(\theta_{t}\right) V\left(\theta_{t}\right)=\sum_{\theta_{t+1}} \lambda\left(\theta_{t+1}\right) \pi_{t+1}+\sum_{\theta_{t+1}} \lambda\left(\theta_{t+1}\right) V\left(\theta_{t+1}\right)-\sum_{\theta_{t+1}} \lambda\left(\theta_{t+1}\right) I_{t+1} .
$$

Noting that $D_{t+1}=\pi_{t+1}-I_{t+1}$, we obtain

(A.21)

$$
\sum_{\theta_{t}} \lambda\left(\theta_{t}\right) \vee\left(\theta_{t}\right)=\sum_{t+1}\left(1+D_{t+1} / V_{t+1}\right) \lambda\left(\theta_{t+1}\right) \vee\left(\theta_{t+1}\right)
$$


By hypothesis, $D_{t+1} / V_{t+1} \geqslant \epsilon>0$, which implies

$$
\sum_{\theta_{t}} \lambda\left(\theta_{t}\right) \vee\left(\theta_{t}\right) \geqslant(1+\epsilon) \sum_{t+1} \lambda\left(\theta_{t+1}\right) \vee\left(\theta_{t+1}\right)
$$

Recursive substitution shows

$$
\sum_{\theta_{t}} \lambda\left(\theta_{t}\right) \vee\left(\theta_{t}\right) \leqslant(1+\epsilon)^{-t} \lambda_{0} V_{0}
$$

Since $\epsilon>0,(A .23)$ implies the tranversality condition is satisfied.

In this case, the equilibrium can be represented as the optimum of the social planning problem defined above.

Q.E.D.

\section{Proof of Proposition 2:}

The capital market equilibrium condition (1.4) implies that

$$
\sum_{\theta_{t+1}} \mid \theta_{t} R\left(\theta_{t+1}\right) p\left(\theta_{t+1} \mid \theta_{t}\right) v^{\prime}\left(c_{t+1}^{0}\left(\theta_{t+1}\right)\right) / u^{\prime}\left(c_{t}^{y}\left(\theta_{t}\right)\right)=1
$$

Setting $j$ equal to zero in (A.11) and substituting into (A.24) yields

$$
\text { (A.25) } \quad \lambda\left(\theta_{t}\right)=\sum_{\theta_{t+1} \mid \theta_{t}}^{R\left(\theta_{t+1}\right) \lambda\left(\theta_{t+1}\right)}
$$

from which it follows

$$
\lambda\left(\theta_{t}\right) V\left(\theta_{t}\right)=\sum_{t+1} \sum_{t} R\left(\theta_{t+1}\right) \lambda\left(\theta_{t+1}\right) V\left(\theta_{t+1}\right)\left[V\left(\theta_{t}\right) / V\left(\theta_{t+1}\right)\right]
$$

Recalling that $G\left(\theta_{t+1}\right) \equiv V\left(\theta_{t+I}\right) / V\left(\theta_{t}\right)$, equation $(A .26)$ implies

$$
\lambda\left(\theta_{t}\right) V\left(\theta_{t}\right)={ }_{\theta_{t+1}} \sum_{t}\left[R\left(\theta_{t+1}\right) / G\left(\theta_{t+1}\right)\right] \lambda\left(\theta_{t+1}\right) V\left(\theta_{t+1}\right)
$$

Now sum both sides of $(A .27)$ over $\theta_{t}$ to obtain 
(A.28)

$$
\sum_{t} \lambda\left(\theta_{t}\right) \vee\left(\theta_{t}\right)=\sum_{t+1}^{\sum}\left[R\left(\theta_{t+1}\right) / G\left(\theta_{t+1}\right)\right] \lambda\left(\theta_{t+1}\right) \vee\left(\theta_{t+1}\right)
$$

Therefore, if $R\left(\theta_{t+1}\right) / G\left(\theta_{t+1}\right) \geqslant 1+\epsilon>1$, then (A.22) and (A.23) hold, which verifies the transversality condition. In this case, the equilibrium can be represented as the optimum of the social planning problem defined above.

If $R\left(\theta_{t+1}\right) / G\left(\theta_{t+1}\right) \leqslant 1-\epsilon<1$, then

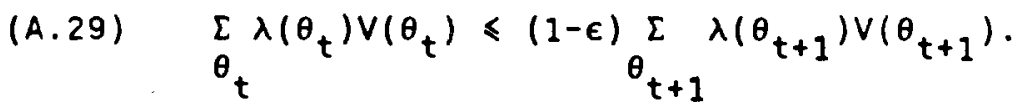

Recursive substitution yields

$$
\sum_{\theta_{t}} \lambda\left(\theta_{t}\right) V /\left(\theta_{t}\right) \geqslant(1-\epsilon)^{-t} \lambda_{0} V_{0} .
$$

(A.30) implies the transversality condition cannot be satisfied. Hence, the equilibrium cannot maximize any social welfare function of the form in equation (1.12).

Note that the social welfare function in $(1.12)$ is linear in $\Omega\left(\theta_{t}\right)$. This proof can be applied to a general social welfare function that is non-linear in $\Omega\left(\theta_{t}\right)$. In this case, $\mu\left(\theta_{t}\right)$ can be interpreted as the derivative of social welfare with respect to $\Omega\left(\theta_{t}\right)$ evaluated at the equilibrium.

Q.E.D. 


\section{Footnotes}

1. If new firms are regularly being started with new equity issues, the aggregate dividend as we define it may always be negative, even when existing firms always pay positive dividends.

2. That it is easier to measure cash flow than economic income has been a major theme in discussions of the consumption tax, such as those presented in Pechman (1983).

3. As noted above, rental income includes imputed rent on owner-occupied housing. The imputed rent estimates in the National Income Accounts upon which we rely indicate that the gross rental rate on owner-occupied housing is considerably lower than the rate on other kinds of capital. Thus, excluding owner-occupied housing would reinforce our conclusion.

4. Suppose that $1+g+\nu_{t+1}$ is lognormally distributed with mean $1+g$. In this case, $\ln \left(1+g+\nu_{t+1}\right) \sim \mathrm{N}\left(\mu, \sigma^{2}\right)$ and

$$
E\left(1+g+\nu_{t+1}\right)=\exp \left(\mu+1 / \sigma^{2}\right) \text {. }
$$

It follows from (F1) and (F2) that

$$
E\left[\left(1+g+\nu_{t+1}\right)^{-1}\right]=\exp \left(\sigma^{2}\right) / E(1+g+\nu t+1) \text {. }
$$

Recalling that $E\left(1+g+\nu_{t+1}\right)=1+g$ and substituting (F3) into (3.5) yields

$$
R_{t+1}^{F}=[(1+g) / \beta] \exp \left(-\sigma^{2}\right)
$$

For sufficiently large $\sigma^{2}, R^{F}$ will be less than one.

5. The results of Mehra and Prescott (1985) suggest that observed consumption variability cannot itself explain the spread between the return on capital and the safe rate of interest. Our point is that a low safe rate is 
not, in itself, inconsistent with dynamic efficiency.

6. Tirole shows that bubbles can drive an economy to the Golden Rule. Our finding of a strictly positive dividend indicates that the capital stock is strictly below the Golden Rule, in which case bubbles cannot exist.

7. Of course, our results do not speak to the possibility of irrational bubbles, or fads, such as those discussed by shiller (1984) and summers $(1986)$. 


\section{References}

Barro, R., "Are Government Bonds Net Wealth?" Journal of Political Economy, vol. $82(6)$ (November-December 1974), pp. 1095-1117.

Cass, D., "On Capital Overaccumulation in the Aggregative Neoclassical Model of Economic Growth: A Complete Characterization," Journal of Economic Theory, vol. 4(2) (April 1972), pp. 200-223.

Christianson, L., "Entrepreneurial Income in Theory and Fact," American Economic Review, 1971.

Diamond, P., "National Debt in a Neoclassical Growth Model," American Economic Review, vol. 55 (1965), pp. 1126-1150.

Feldstein, M.S., "Perceived Wealth in Bonds and Social Security. A Comment," Journal of Political Economy, vol. 84(2) (April 1976), pp. 331-336.

Feldstein, M.S., "Does the United States Save Too Little?" American Economic Review, vol. 67(1) (February 1977), pp. 116-121.

Feldstein, M.S., and Summers, L., "Is the Rate of Profit Falling?" Brookings Papers in Economic Activity (1977:1), pp. 211-227.

Ibpotson, R.G., Stocks, Bonds, Bills, and Inflation Market Results for

1926-1983. 1984 Yearbook. R.G. Ibbotson Associates, Inc., Chicago (February 1984).

Lucas, R.E., "Asset Prices in an Exchange Economy," Econometrica, vol. 46(6) (November 1978), pp. 1429-1445.

Mehra, R., and Prescott, E., "The Equity Premium: A Puzzle," Journal of Monetary Economics, vol. 15(1) (January 1985), pp. 145-161.

Mishkin, F.S., "The Real Interest Rate: A Multi-Country Empirical Study," Canadian Journal of Economics, vol. 17 (May 1984), pp. 283-311. 
Pechman, J. (ed.), what Should Be Taxed: Income or Expenditure? The Brookings Institution, Washington, DC (1983).

Phelps, E.S., "The Golden Rule of Accumulation: A Fable for Growthmen," American Economic Review, vol. 51 (September 1961), pp. 638-643.

Phelps, E.S., Golden Rules of Economic Growth, Norton, New York and North Holland, Amsterdam (1966).

Samuelson, P., "Why We Should Not Make Mean Log of Wealth Big Though Years to Act Are Long," Journal of Banking and Finance (1979), pp. 305-307.

Shiller, R., "Stock Prices and Social Dynamics," Brookings Papers on Economic Activity $1984: 2$, pp. 457-498.

Solow, R., Growth Theory: An Exposition, Oxford University Press, New York and oxford (1970).

Summers, L., "Does the Stock Market Rationally Reflect Fundamental Values?" Journal of Finance, vol. 41(3) (July 1986), pp. 591-601.

Tirole, J., "Asset Bubbles and Over lapping Generations," Econometrica, vol. 53(6) (November 1985), pp. 1499-1528.

Tobin, J., "Economic Policy Towards Growth," in Collected Papers of James Tobin, vol. 1 (1965).

Weil, P., "'Love Thy Children': Reflections on the Barro Debt Neutrality Theorem," mimeo (June 1986). 
Table 1

Gross Profit and Investment: The United States Economy (Percent)

\begin{tabular}{|c|c|c|c|c|}
\hline Year & $\frac{\text { Gross Profit }}{\text { GNP }}$ & $\frac{\text { Gross Investment }}{\text { GNP }}$ & $\frac{D}{\text { GNP }}$ & $\frac{D}{V}$ \\
\hline 1929 & 32.6 & 16.1 & 16.5 & $\cdots$ \\
\hline 1930 & 31.7 & 11.6 & 20.1 & -- \\
\hline 1931 & 28.6 & 7.7 & 20.9 & -- \\
\hline 1932 & 26.4 & 1.9 & 24.5 & - \\
\hline 1933 & 24.6 & 2.9 & 21.8 & -- \\
\hline 1934 & 26.1 & 5.3 & 20.8 & -- \\
\hline 1935 & 27.1 & 9.1 & 18.0 & -- \\
\hline 1936 & 26.4 & 10.5 & 15.9 & -- \\
\hline 1937 & 26.9 & 13.3 & 13.6 & -- \\
\hline 1938 & 26.5 & 7.8 & 18.6 & -- \\
\hline 1939 & 26.7 & 10.4 & 16.3 & -- \\
\hline 1940 & 28.2 & 13.3 & 14.9 & -- \\
\hline 1941 & 29.4 & 14.6 & 14.8 & -- \\
\hline 1942 & 29.0 & 6.5 & 22.6 & -- \\
\hline 1943 & 27.2 & 3.2 & 24.0 & -- \\
\hline 1944 & 25.2 & 3.6 & 21.5 & -- \\
\hline 1945 & 23.2 & 5.3 & 17.9 & -- \\
\hline 1946 & 24.0 & 14.8 & 9.2 & -- \\
\hline 1947 & 25.6 & 14.9 & 10.8 & -- \\
\hline 1948 & 27.8 & 18.0 & 9.8 & -- \\
\hline 1949 & 27.3 & 14.0 & 13.3 & $\cdots$ \\
\hline 1950 & 28.4 & 19.1 & 9.3 & -- \\
\hline 1951 & 28.0 & 18.1 & 9.9 & -- \\
\hline 1952 & 26.9 & 15.2 & 11.7 & 3.9 \\
\hline 1953 & 26.4 & 14.8 & 11.6 & 4.0 \\
\hline 1954 & 26.9 & 14.5 & 12.4 & 4.1 \\
\hline 1955 & 28.2 & 17.2 & 11.0 & 3.7 \\
\hline 1956 & 27.6 & 17.0 & 10.6 & 3.4 \\
\hline 1957 & 27.4 & 15.8 & 11.6 & 3.8 \\
\hline 1958 & 27.0 & 13.9 & 13.1 & 4.1 \\
\hline 1959 & 27.8 & 16.2 & 11.6 & 3.8 \\
\hline 1960 & 27.1 & 15.2 & 11.9 & 3.9 \\
\hline 1961 & 27.1 & 14.4 & 12.7 & 4.2 \\
\hline 1962 & 27.4 & 15.2 & 12.1 & 4.1 \\
\hline 1963 & 27.6 & 15.3 & 12.3 & 4.2 \\
\hline 1964 & 27.7 & 15.3 & 12.4 & 4.3 \\
\hline 1965 & 28.2 & 16.5 & 11.8 & 4.2 \\
\hline 1966 & 27.8 & 16.7 & 11.1 & 4.0 \\
\hline 1967 & 27.2 & 15.4 & 11.8 & 4.2 \\
\hline 1968 & 26.6 & 15.3 & 11.3 & 4.0 \\
\hline 1969 & 25.7 & 15.9 & 9.8 & 3.5 \\
\hline
\end{tabular}


Table 1, Continued

\begin{tabular}{|c|c|c|c|c|}
\hline Year & $\frac{\text { Gross Profit }}{\text { GNP }}$ & $\frac{\text { Gross Investment }}{G N P}$ & $\frac{D}{G N P}$ & $\frac{D}{V}$ \\
\hline 1970 & 24.6 & 14.7 & 9.9 & 3.5 \\
\hline 1971 & 25.2 & 15.6 & 9.6 & 3.4 \\
\hline 1972 & 25.6 & 16.7 & 8.9 & 3.1 \\
\hline 1973 & 25.6 & 17.6 & 8.1 & 2.8 \\
\hline 1974 & 25.1 & 16.3 & 8.8 & 2.8 \\
\hline 1975 & 26.2 & 13.7 & 12.4 & 3.9 \\
\hline 1976 & 26.4 & 15.6 & 10.8 & 3.4 \\
\hline 1977 & 27.1 & 17.3 & 9.9 & 3.1 \\
\hline 1978 & 27.6 & 18.5 & 9.1 & 2.7 \\
\hline 1979 & 27.6 & 18.1 & 9.5 & 2.8 \\
\hline 1980 & 27.4 & 16.0 & 11.4 & 3.2 \\
\hline 1981 & 28.1 & 16.9 & 11.2 & 3.2 \\
\hline 1982 & 27.7 & 14.1 & 13.6 & 3.9 \\
\hline 1983 & 28.4 & 14.7 & 13.7 & 4.0 \\
\hline 1984 & 28.5 & 17.6 & 10.9 & 3.3 \\
\hline 1985 & 28.0 & 16.5 & 11.5 & 3.6 \\
\hline
\end{tabular}

Source: NIPA. Capital Cash Flow is calculated as national income plus capital consumption allowances less wages and salaries and 67 percent of proprietors' income which is imputed to labor. This imputation is discussed in Christianson (1971). 
Table 2

Gross Profit and Investment:

The U.S. Nonfinancial Corporate Sector

(Percent)

\begin{tabular}{|c|c|c|c|}
\hline Year & $\frac{\text { Gross Profit }}{V}$ & $\frac{\text { Gross Investment }}{V}$ & $\frac{D}{V}$ \\
\hline 1952 & NA & NA & NA \\
\hline 1953 & 29.1 & 14.7 & 13.6 \\
\hline 1954 & 28.7 & 13.3 & 14.3 \\
\hline 1955 & 25.1 & 13.3 & 10.2 \\
\hline 1956 & 21.0 & 12.3 & 7.0 \\
\hline 1957 & 19.4 & 10.8 & 7.5 \\
\hline 1958 & 20.6 & 9.6 & 10.0 \\
\hline 1959 & 18.2 & 9.8 & 7.6 \\
\hline 1960 & 16.7 & 9.2 & 6.3 \\
\hline 1961 & 16.9 & 8.9 & 7.5 \\
\hline 1962 & 15.5 & 8.9 & 6.9 \\
\hline 1963 & 18.0 & 9.8 & 8.0 \\
\hline 1964 & 17.1 & 9.5 & 7.3 \\
\hline 1965 & 17.5 & 10.5 & 6.9 \\
\hline 1966 & 17.4 & 11.7 & 5.9 \\
\hline 1967 & 18.4 & 11.6 & 6.9 \\
\hline 1968 & 16.1 & 9.7 & 6.2 \\
\hline 1969 & 14.6 & 9.5 & 5.7 \\
\hline 1970 & 15.5 & 9.9 & 5.6 \\
\hline 1971 & 16.9 & 10.4 & 6.8 \\
\hline 1972 & 16.7 & 10.2 & 6.5 \\
\hline 1973 & 17.7 & 11.4 & 5.7 \\
\hline 1974 & 23.9 & 15.6 & 5.5 \\
\hline 1975 & 31.5 & 15.4 & 14.4 \\
\hline 1976 & 29.7 & 17.4 & 10.3 \\
\hline 1977 & 30.0 & 17.6 & 9.6 \\
\hline 1978 & 34.3 & 21.4 & 9.9 \\
\hline 1979 & 35.7 & 21.9 & 12.4 \\
\hline 1980 & 31.7 & 18.9 & 10.2 \\
\hline 1981 & 26.6 & 16.9 & 7.1 \\
\hline 1982 & 25.3 & 15.1 & 7.9 \\
\hline 1983 & 23.5 & 14.1 & 9.3 \\
\hline 1984 & 23.4 & 17.3 & 6.7 \\
\hline 1985 & 22.1 & 15.9 & 8.5 \\
\hline
\end{tabular}


Table 3

Dynamic Efficiency in Different Countries

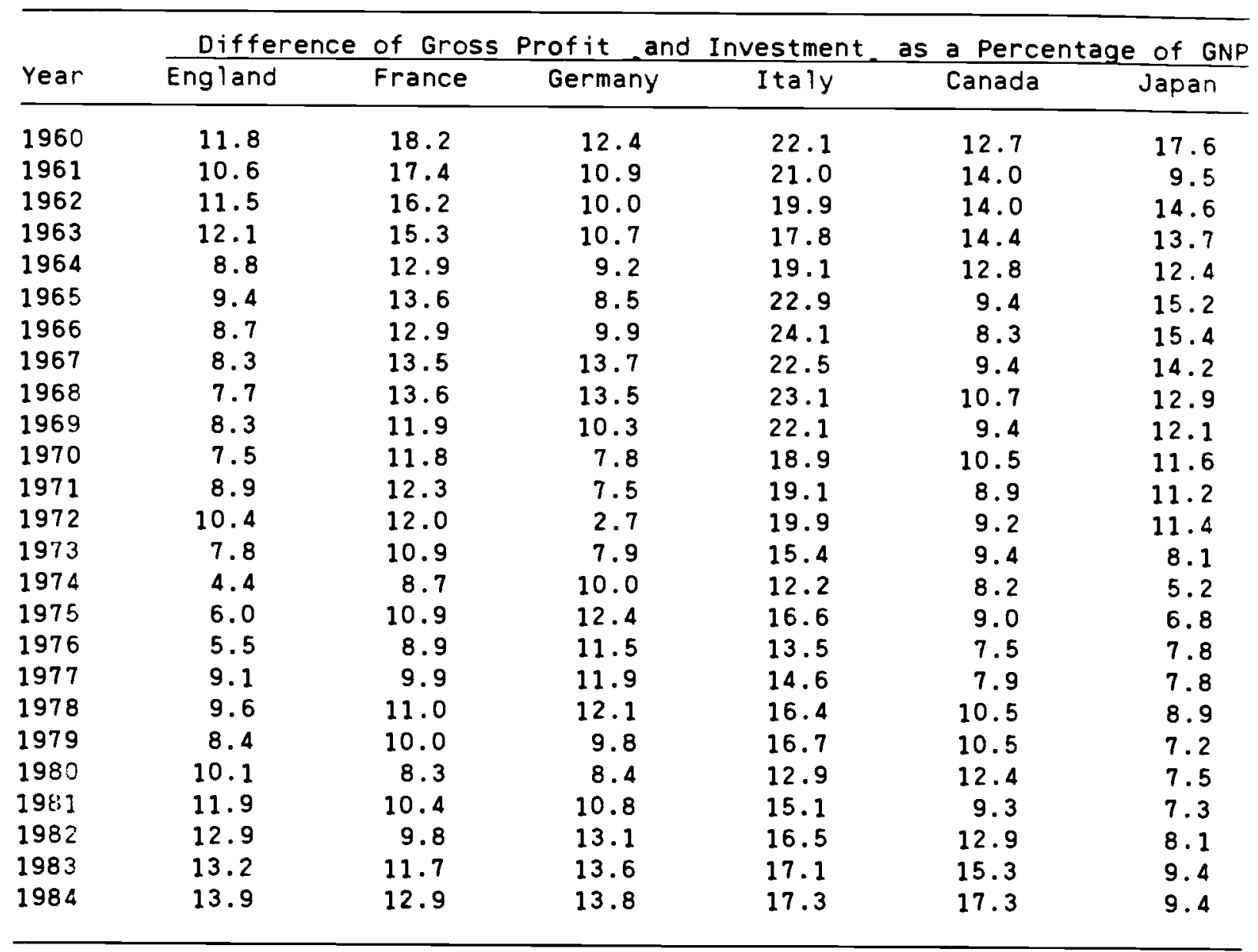

Source: OECD. These data are in some cases not adjusted for the labor income of proprietors. As discussed by Sachs (1979), this approximation is quite innocuous. For the United State, the adjustment is equal to about 4 percent of GNP. 